\title{
FROM DAGUERREOTYPES TO DIGITAL AUTOMATIC PHOTOGRAMMETRY. APPLICATIONS AND LIMITS FOR THE BUILT HERITAGE PROJECT.
}

\author{
F. Fassi ${ }^{a}$, C. Campanella ${ }^{\text {a }}$ \\ a Politecnico di Milano - Dep. ABC - (francesco.fassi, christian.campanella)@polimi.it
}

Commission II, WG VIII

KEYWORDS: Photogrammetry, photography, conservation, restoration

\begin{abstract}
:
This paper will describe the evolutionary stages that shaped and built, over the time, a robust and solid relationship between 'indirect survey methods' and knowledge of the 'architectural matter', aiming at producing a conservation project for the built heritage. Collecting architectural data by simply drawing them was considered to be inadequate by John Ruskin already in 1845 . He strongly felt the need to fix them through that 'blessed' invention that was the 'daguerreotype.' Today taking simple photographs is not enough: it is crucial to develop systems able to provide the best graphics supports (possibly in the third dimension) for the development and editing of the architectural project.

This paper will focus not only on the re-examination of historical data, on the research and representation of the 'sign', but also on the evolution of technologies and 'reading methods', in order to highlight their strengths and weaknesses in the real practice of conservation project and in the use of the architectures of the past.
\end{abstract}

\section{INTRODUCTION}

\subsection{From Sketch to photography till to photogrammetry}

"Well, among all the poisons of the mechanics that this terrible XIX century it fob off us, we are not able to enumerate the healthy antidote that is the daguerreotype. In addition, indeed a blessed invention, here the thing is. (...) It is really a beautiful thing to be able to count on every detail." (Ruskin, 2002) In this way, the young Ruskin in 1845 celebrated the importance of the great innovations of the century. A new and incredible means capable of reproducing reality of constructed without tricks or lies, often linked to the pictorial representation. The 24 April of the same year, he wrote to his father from Oneglia underlining in few words the extraordinariness of the truth and the reality. "How foolish are our artists that despite these extraordinary models lying on every step, they don't know how to do better nothing of their fools vintages and "tarantelle", where every skirt and new every jacket appear immaculate. How spectacular it is the dirty." (Ruskin, 2002).

The great need of truth, to accumulate information brought Ruskin to use and supporting of the "sketch realized with the light", of the daguerreotype that "has been given there, I believe, really in time to save some testimony of the great public of the destroyers.". (Bignardi, 1986). In a letter dated 7 October 1845, sent from Venice to his father, Ruskin still writes that shutting a daguerreotype is "as bring away with you the same building. Every fragment of stone and every stain is seen and naturally there are no error respect to the proportions" and "almost a magician had made smaller the reality in order to take it away." (Costantini, 1986) No sketch, he observes, can illustrate the deterioration of a city better as a daguerreotype, that also defines in detail the cracks of the plaster on the walls, with a so rigorous and perfection, that any draftsman would be able to reach.

The photo appears to Ruskin, as to many his contemporaries, first among all William Henry Fox Talbot, photographer and inventor of the Calotype. This photographic procedure allowed the reproduction of the images with the negative/positive method. He calls it "pencil of the nature" (in 1844 it published the volume The Pencil of natures), the form most faithful and transportable reproduction. It was introduced to the Royal Society seven months later than the photographic process of Louis Daguerre, the daguerreotype. This delay made to lose importance to the calotype, also because the method used by Talbot was more "hard-working" than the process presented by Daguerre, and of inferior quality. The invention of the photographic procedures got, from the beginning of second half the 800 , the birth of a new profession: the photographer. The first experiments (from daguerreotype of the 1839 to the calotype of the 1841 up to the first photos printed with the albumin in 1848) remained confined to a narrow circle of students and of enthusiasts. It was only thanks to the new techniques of the damp collodion (1851) and subsequently of the dry one what the field of the photographic routine widened.

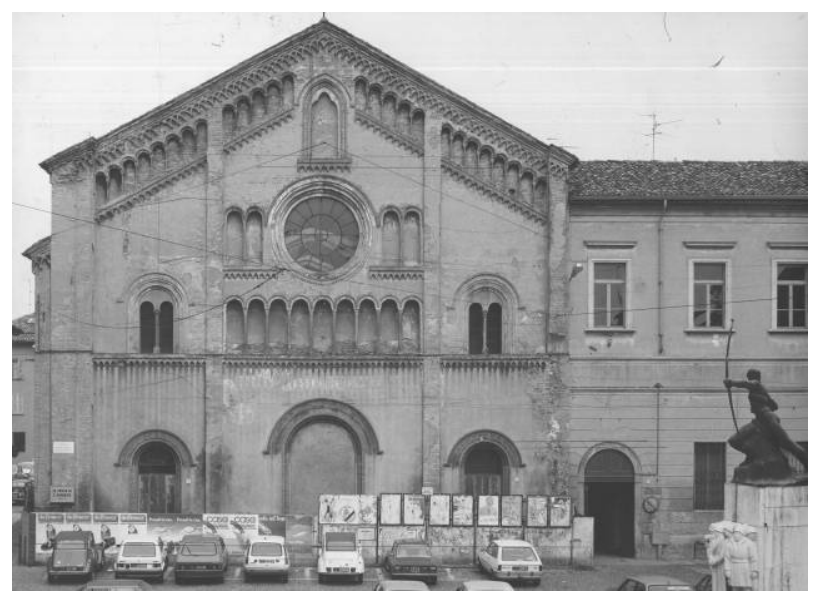

Figure 1: Church of San Domenico in Crema (Cr) 1984. The rectified image has been taken directly photographically with a reflex camera with a tilt-shift lens and later plotted at 1:50 scale. (Degree Thesis, Campanella Zucchetti)

A production that assumed proportions of real "professional activity" at the beginning of 1860 , when new physical and chemical technologies allowed a further lowering photographic 
exposure time and a further simplification both of the machineries and of the chemical and physical technologies.

Already in the 1839, Macedonio Melloni had written "who would have believed few months ago, that the light, penetrable, intangible, imponderable, deprived in short of all the ownerships of the subject, would have assumed the charge of the painter properly drawing herself and with the most delicious mastery?". (Melloni, 1839). The contemporaries had already noticed this real photographic revolution. They wrote on the "Gazzetta Milanese" of 1839, 15th January: "there is a revolution in the art of the sketch and engraving (...) because through this process the nature itself will be reproduced in blink of an eye, without any human intervention." They were not only simple reporters to acknowledge the importance of this new idea, since also Carlo Cattaneo write about photography on the Polytechnic "the operation doesn't ask for any expertise of sketch or any particular mastery. Observing few simple rules, everyone can succeed as the same Daguerre." (Burgio, 2009).

The photo spread and takes space in the field of "architectural reading", of documentation and representation. It does not replace the sketch, or not immediately at least. It becomes in the time an important tool so much to give impulse and development to the photogrammetric survey since from the beginning of 1851 when some measures were taken using images by the frames using a methods similar to the triangulation, even getting notable errors caused by the distortion of the photographic objectives.

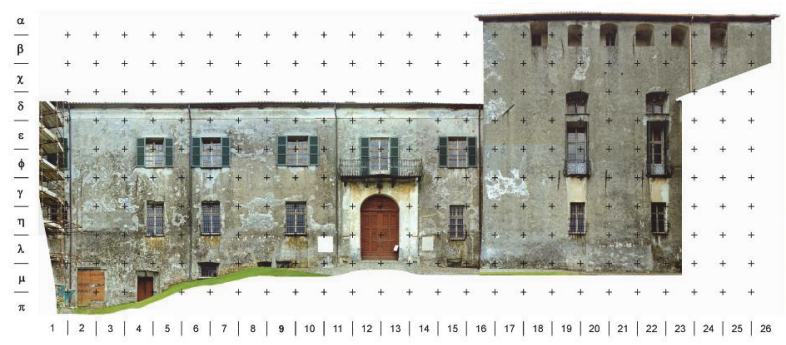

Figure 2: Castello di Masino (To) 1997: Orto-photographic survey with the system Real View (by Vectar, Arezzo).

Employment of semiautomatic film reflex camera Canon Eos 500 with $50 \mathrm{~mm}$ lens and 100 ASA colour film Kodak. (T.

Kirova, C. Campanella)

The job and the constant research of a methodology able to numerically reproduce the dimensions of an object through the photo crossed the whole second half of the 1800 and the first half of the 1900 with the inventions of the "fotogoniometro" (1865) of Ignazio Porro, the stereoscopy, the "stereoautograph" of Von Orel.

The First World War saw then the great development of the aerial photogrammetry, while the terrestrial photogrammetry or close range photogrammetry was employed for the survey of the buildings.

Obviously, the advent of the electronics, at the beginning of the years ' 60 , with equipment with great ability of calculation and small dimensions, gave a lot of impulse to photogrammetry directing it toward an analytical formulation. This lets theoretically to formalize the possibility to obtain an orthogonal projection from a stereoscopic couple of images through the numerical development of a certain quantity of equations elaborated by the computer.

At the beginning of the ' 90 , it become finally possible to produce and to use not only photographic, but also numerical images, digital images, structure that is in a matrix of small elements called pixel. The employment of these images has resulted in the digital phase of the photogrammetry.

\section{PHOTO AND MAPPING FOR THE MAINTENANCE OF THE ARCHITECTURE.}

The measure of the geometries of a building is exclusively able to return a uniform image of the investigated manufactured article, an abstract, linear profile that is purified by every element and indication that do not have spatial evidence and metric determination. This image built with planes, lines and measures, do not give therefore any qualitative information on the subject. The voids and the full that compete to define a building are the result of the presence and of the interaction of various material, assembled and places in work according to specific formalities. The health and the duration of the building depend, de facto, from the ability to withstand the time (with all the consequent problems) and of the material of which it is composed.

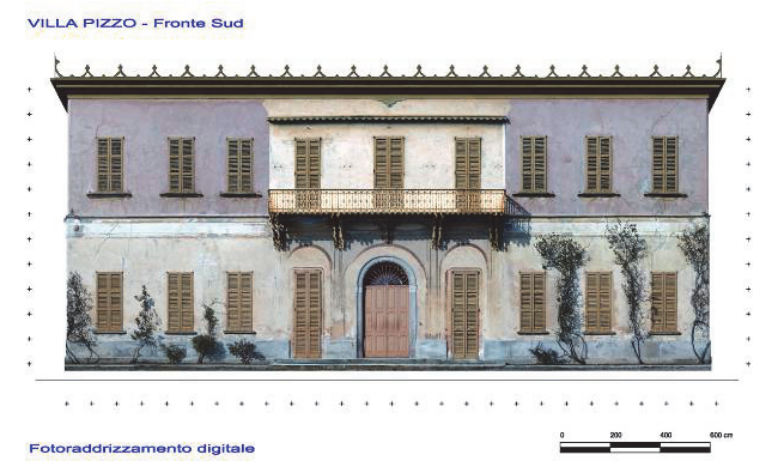

Figure 3 Villa Pizzo (Co) 2001. Rectified image at 1:50 scale. Created using a film camera reflex Canon Eos 500 with $50 \mathrm{~mm}$ lens and 100 ASA Kodak colour film. 21 photos were used to cover the front, with an overlap of the 60 percent both transversally and longitudinally. The photographic images are acquired with scanner to the resolution of 200 dpi. (Studio Campanella Tessoni)

The individualization and the technological description of the materials that constitute an architectural complex, the recognition and the description of the pathologies in aggression, of the causes that have produced the pathogenesis; they have to find their representative formality through the predisposition of tables of the "material and pathological survey". These graphical elaborations have the difficult role to make the most exhaustive as possible the informative picture on the characteristics of the building manufactured article that is deduced through the execution of the analyses preparatory to the project of intervention. They are complementary elaborations of the geometric survey that becomes the irreplaceable base on which it is to connect all the physical, chemical, structural specificities of the elements that constitute the factory.

The quantity of picked information through the preventive investigations and the direct observation on the field can in this way converge in a single graphic product at the correct representation scale. It could be an image of the object very similar to the reality, or one simplification of it, using more composition, schematizing the problems and referring to technical sheets and in-depth analysis.

It will be possible to go deeply with a top-down approach choosing the representation manner in base to the information 
that has to be transmitted in direct way. Employing as base the geometric survey or accurate photogrammetric restitutions, it is possible to come to delimit homogeneous zones for type of material, to individualize lesions, yielding, technological solutions, formality of laying, bands interested by diffused or punctual pathologies, drawing the information through hatch pattern, colours, text and symbols etc.

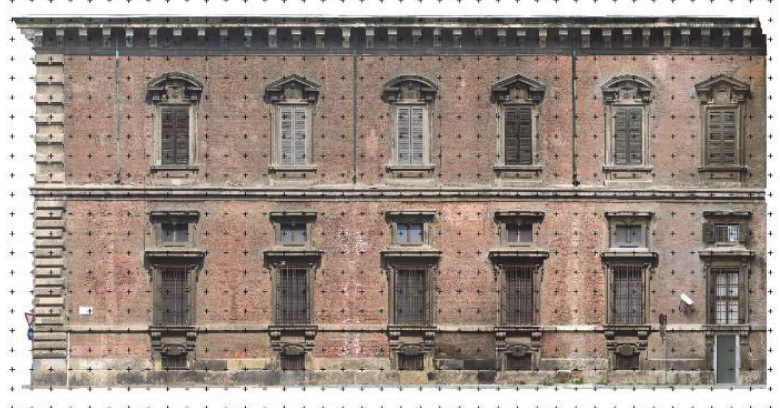

Figure 4: Palazzo Brera (Mi) 2003. Forehead on "Piazzetta

Brera" rectified image to the scale 1:50. The photographic acquisition was done with not-metrics digital camera Olympus C-3040 zoom - 3,3 megapixels. The 38 photos with a resolution of 2040x 1536 pixels of the fronts were taken with an overlap of the 60 percent, both transversally and longitudinally. They were

elaborated with the software RASTA of the SierraSoft Geomatics. (Studio Campanella Tessoni)

The first mapping able to underline and to define the picture of pathology and material of an existing architecture, back to the first years of ' 80 s and initially they are created as live drawing of the building, a kind of "drawn photo" to which it is possible refer for identifying material and decay. From the simple graphic restitution to an identification of material and degradation through acronyms and numerations the footstep is brief.

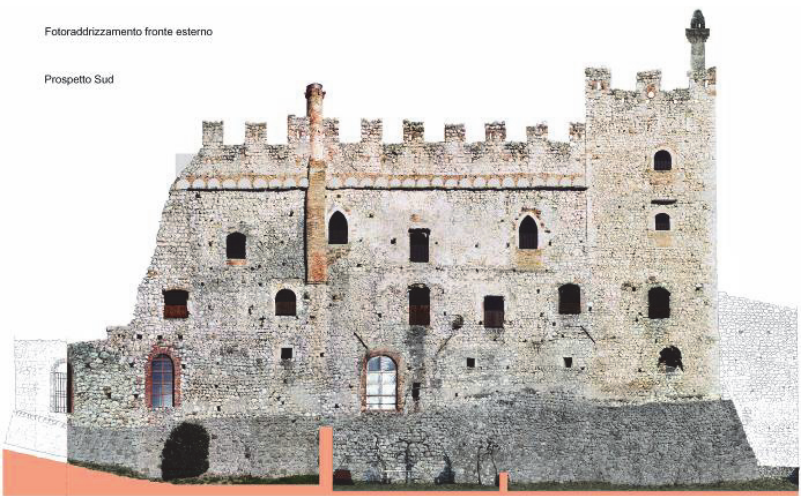

Figure 5: Castello di Avio 2002 (Tn). Rectified Image (1:50) of the inside fronts of the baronial building of the castle of Avio,

(Studio Campanella Tessoni).

The graphic representations through hatches patterns born a little later and they find a first, and currently the only, standardization through the recommendation Normal $1 / 88$ (Macroscopic Alteration of the Stone Material).

Once more it is looked for support in the photographic technique for speed up the restitutions, often using him as base and support to redraw (on paper, acetate, shiny) the state "to the reality" of studied object. There is a problem of orthogonality of the images and of perspective deformation that can be solved with photogrammetry (complex and onerous) using metric or semi-metric cameras.

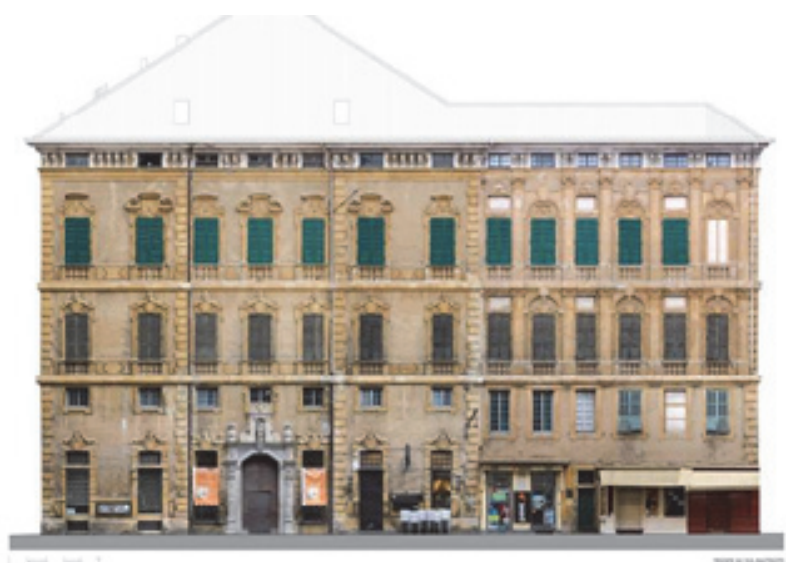

Figure 6: Palazzo Borea D’Olmo (Im) 2014. Photographic rectification realized on July 72014 using reflex camera Canon $6 \mathrm{D}$ with sensor full-frame from 20 Mpixel and optics zoom 17$40 \mathrm{~mm} \mathrm{f} / 4 \mathrm{~s}$ and $28-70 \mathrm{~mm} \mathrm{f} / 2.8$. To notice the use of wide angle lens to get the façade with a possible capture distance of only 4 meters. The images have been taken using an elevator platform

to get the images in quota, minimizing the perspective

distortions and reducing the blind angles caused by the projections of the decorative apparatus. The image rectification was done using the software Photometric of Geopro after the

correction of the radial distortion of every photo The rectification has been performed employing "analytical methodology" using support Ground Control Points measured with Topcon GPT 3005 total station. (Studio Campanella Tessoni).

In the mid-90s, with the advent of the electronics (computer, Autocad) and more flexible survey systems, new techniques of representation and mapping are developed integrating photos, sketches and information. Abandoned the reproduction and the sketch on glossy paper (only and exclusively in black and white) a brief season that exploits the new digital trends in the restoration field: AutoCAD drawings, scanner able do digitalize photos and documents, programs of photo-mosaic and photo editing. The idea is to use new technologies but still using the traditional photo acquisition that needed low sensibility films, images releases with good depth of field and with normal lenses not less of $35 \mathrm{~mm}$. In this way, it is possible to proceed to the create photographic images of high scan quality, to scan, importing, photo mosaicking with the first software of photorectification of the image.

The first great revolution is the arrival of digital cameras, and the development of digital image elaboration (as Photoshop in 1991), the panorama expand itself to the today's techniques of image capture and 3D measuring using photos daughters of the terrestrial photogrammetry of the last generation. (Campanella, 2017)

\section{THE EVOLUTION OF THE PHOTOGRAMMETRIC SURVEY METHODOLOGY}

\subsection{The photogrammetric products for architectures}

The main "photogrammetric products" useful for restoration purposes has always been 2D stereo plotting, rectified images and orthophotos.

2D stereo plotting is the classical method of extracting measures from photos and it is adopted from aerial photogrammetry and cartography. It lets to digitalize simple 3D and in general planar views (horizontal or vertical) from a photogrammetric stereo pair, it is the photogrammetric way to 
produce the classical representations of architecture. The product was normally a drawing in CAD format. In this case, the images were only an intermediate medium to extract $2 \mathrm{D}$ or 3D simplified geometric information.

The other two products (rectified images and orthophotos) are "metric images" that are the result of a post-processing of photogrammetric type: they are the orthographic projected view of an object on a chosen projection plane. For this characteristic, these images can be measured allowing 2D measures on the reference plane (only!). Conceptually they are like prospects and classical architectural representations, but instead of being drawn, that means reworked, interpreted and simplified by the operator, they represent the object photographically in all its features, not only geometric (that means measurable) but also formal showing for example colour, material and state of preservation. For this reason, they are well known and the most used products to support restoration and maintenance activities.
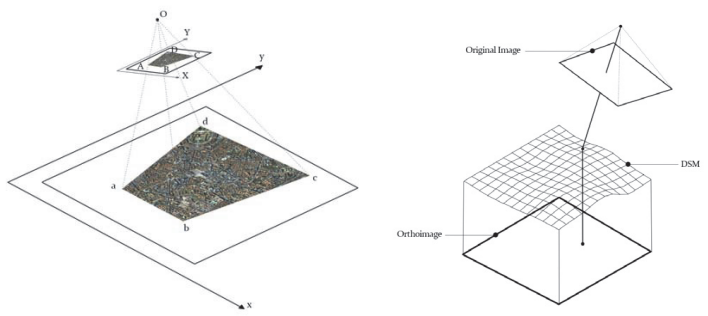

Figure 7: On the left the rectified image construction schema.

On the right the orthophoto simple schematization.

Simplifying the concept, both product are based on the principle of projection of the oriented images to its $3 \mathrm{D}$ model and the subsequent its projection on the chosen plane, that best approximates it. Rectified image is a simplified orthophoto and can be applied only when the object can be assumed as planar, when any architectonical protrusion is negligible. This assumption lets to simplify the photogrammetric mathematical model of the collinearity equation because it neglects the depth of the object assuming that is perfectly flat. That means that the restitution requires only one photo, and that a rectified image can be done geometrically applying a homographic transformation to the image.

For this reason, it is a "simple" and popular method to represent facades or in general architectonic planar element. Advantages of this technique are the extremely simple and fast process that not requires special expertise and the complex and time consuming photogrammetric alignment process. Moreover, it is possible to avoid a topographic support survey. Working directly on single photos, eventually mosaicking manually many single rectified images to compose the whole object, allows producing a final image characterized by good image quality with no lack of information and no shadow areas. However, pay attention, this is only apparent: only what is on the reference projection plane is metrically correct and have the real perspective correction. All the other parts that are out of the plane are not metrically correct and cannot be measured.

All this aspects make a rectified image very popular because simple to be produced but it is an extremely simplified representation, not correct in all its parts.

At the contrary, the orthophoto is the real and correct "orthogonally projected photo". It is the final product of the photogrammetric process and to create it, it is mandatory to have an accurate 3D model (DTM or DSM) of the object. This is the reason why creating an orthophoto was always a big challenge and it has always been underused in the field of restoration and architecture in general. In fact creating a complete, high-resolution and good quality 3D model of the object is not a simple task and require expertise and timeconsuming work and a performing hardware. Once, it was impossible to have high-resolution 3D model of architectures and orthophoto remained for years only matter of cartography: the 3D model of the terrain (DTM) can have lower resolution and is conceptually simpler: it is a 2,5D and not a real 3D.

Long and laborious photogrammetric process and the creation of complex 3D model were the two main reasons why photogrammetry for years was not used in the world of restoration and architecture in general delegating the task of representation to rectified-images or very simplified graphic restitutions. They were the only image-based instruments able to represent building or part of them. High accuracies, large scales of representation and a reality-based representation of objects, however, were impossible to be achieved.

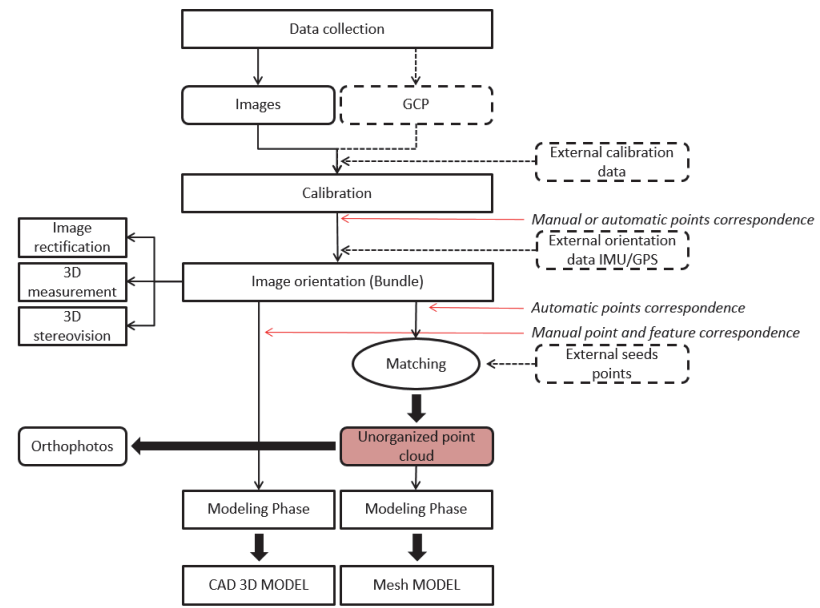

Figure 8: The Photogrammetric Pipeline valid both for the old and new way of making photogrammetry.

\subsection{Architectures and 3D using photogrammetry}

The main issues in the use of images as survey methods when dealing with complex objects such as architectural and archaeological type and in general for small and large objects belonging to the world of Cultural Heritage are the following:

- the richness of detail that must be acquired and represented. This requires high-resolution images and high-resolution 3D modelling procedures;

- the complexity of the artistic free-forms that force the acquisition and the elaboration of a very high number of photos;

- the relation between geometric survey and other qualitative (colour, materials, decay) survey information, often a challenge to be performed in a metric way.

For this reasons, the use of manual or semi-manual photogrammetric methods have until recently prevented or severely limited a complete three-dimensional survey, because of the need to acquire and process a very high number of images required to describe the shape of the object in an adequate way. This has been true obviously over the time of analogue photogrammetry, but it was likewise with the advent of digital photography, because the photogrammetric processing operations, in one way or the other, have always been manual.

For very complex objects, this operation could be extremely difficult or even impossible, not only for the amount of data to be manually processed but also for the real effort of the manual 
or semi-automatic identification of a sufficient number of welldisposed tie points to guarantee a correct bundle adjustment. In the past, these were the real obstacles in the use of photogrammetry in the architectonic survey, resulting uneconomical and therefore useless.

A further issue was the camera calibration, essential step of the photogrammetric process and high accuracy modelling. In the past, it was critical to use accurate and expensive pre-calibrated instrumentation as metric or semi-metric cameras. This has always confined the use of photogrammetric techniques to a few expert operators. Later, around 2000, with the advent of the digital technology, a pre-calibration could be achieved off-site in a more simple way, and thus allow the use of commercial digital cameras. This was the first step that made photogrammetry more familiar and enlarged the number of users, and dramatically reduced the costs and operational limitations.

\subsection{Photogrammetry and Laser scanning.}

High numbers of images and camera pre-calibration were two key factors, which made photogrammetry for close range cases time-consuming, complicated, often inaccurate and sometimes even impossible. This has favoured in the past the use of TLS techniques (Terrestrial Laser Scanning). In 2003, this was the promise of this method: "Laser scanning results in a point cloud, which is a true three-dimensional image of the reality in 1:1 scale. Therefore, all information concerning object geometry is contained completely und without any doubt in the point cloud." And many years later in 2008 Karl Kraus, father of the modern photogrammetry defining that is photogrammetry write: "Photogrammetry allows one to reconstruct the position, orientation, shape and size of objects from pictures: these pictures may originate as photochemical images (conventional photography) or as photoelectrical images (digital photography). Laser scanner images, a third group, have arrived in recent years; laser scanner images have distance information associated with every picture element". (Kraus, 2008)

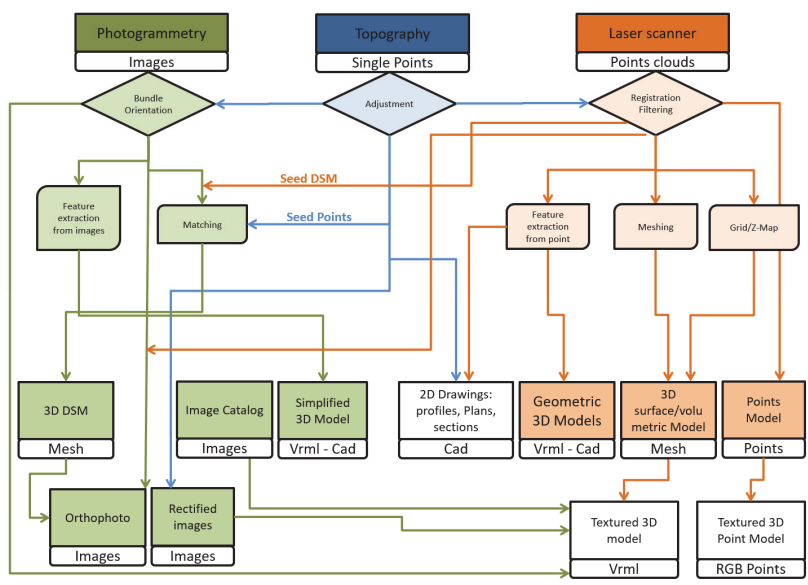

Figure 9: Integration of Photogrammetry, Laser scanning and Topography for Cultural Heritage Complex environment survey.

It is interesting how he defines the laser scanner as a photogrammetric technique and not a topographical one, as it is commonly thought. This is to emphasize that in 2008 the laser scanner is the rescue of photogrammetry allowing the threedimensional acquisition of objects automatically. Although much more expensive, this technique is simpler and faster in the acquisition phase and allows the real-time three-dimensional geometric survey of extended environments and architecture. The product, as said, is a point cloud, which means a 3D discrete model composed by a huge amount of points that describe the measured surface. This type of instrumentation is able to get high resolution 3D of the object but not the colour. All attempts to colour the clouds with integrated digital cameras mounted internally or externally on the instrument allows the colouring of the cloud with the aim to make it more readable, but still today without reaching sufficient levels of metric and radiometric quality.

It was immediate at that time that the integration of two technologies (laser scanning and photogrammetry) was the only way to use high-resolution $3 \mathrm{D}$ geometry as base to create accurate textured 3D models or true-orthophoto and photogrammetry to texture the point cloud in an accurate way. The application of this procedure was only theoretical, matter of research groups, because very time consuming, expensive and computationally problematic because forced to use two technologies to get the final product.

\subsection{The revolution}

In recent years, the marriage between photogrammetry and image analysis, typical of computer vision, revolutionized and is still changing the way to survey objects in $3 \mathrm{D}$, especially in the world of Cultural Heritage. This type of method works following the standard pipeline of photogrammetry but using automatic image-matching methods both in the orientation phase and in the modelling part. The substantial difference lies in the complete automation of each step. In extreme cases, the entire process can be entirely performed automatically by the software without any intervention of the operator. We no longer speak of 'automatic process' but of completely 'autonomous process.'

As said before, it was impossible the survey of complex 3D object with standard manual photogrammetric workflow while Computer Vision always worked on 3D reconstruction developing the automatism in spite of metric accuracy.

The two techniques together creates a revolutionary way to proceed joining the accuracy of photogrammetric process with the automatism typical of CV. This method can be called Image Based Modelling Approach. It involves the possibility to orientate in a short time and without any 'loss of time' a significant number of images, thus allowing the survey of extended environments or complex objects. Moreover, the automatic identification of a huge number of points allows the 'self-calibration' process of the photographic cameras, thus avoiding complex pre-calibration procedures. In this way, the photographic acquisition is freed (up to a certain point!) from the photogrammetric constraints of the past: it regains the characteristic of enormous flexibility and 'easy acquisition,' typical of photography, and allows freedom of movement around the object and a multi-scale acquisition. Moreover, considering the economic aspect of the system, this method proves to be extremely low cost and apparently open to everybody. This means that we now have at our disposal a lowcost method (both hardware and software), sufficiently userfriendly to allows any type of operator to quickly survey every kind of object, with the possibility of describing, model and represent complex objects in 3D and in high resolution.

The products of this kind of methods is a so-called "dense Point cloud" coming from image matching process that lets to reconstruct in $3 \mathrm{D}$, with completeness and accurately an object. Hence, the product of the modelling phase is a $3 \mathrm{D}$ point cloud 
comparable for density and resolution with laser scanner one and it is conceptually the same thing. Further, in the photogrammetric point cloud we have also a metrically accurate information about the colour of the object.

This allows the extraction of accurate measurements using interpolation methods typical of point cloud analysis and the 'automatic' creation of high-resolution accurate realorthophoto. The problem to create the $3 \mathrm{D}$ model is theoretically solved.

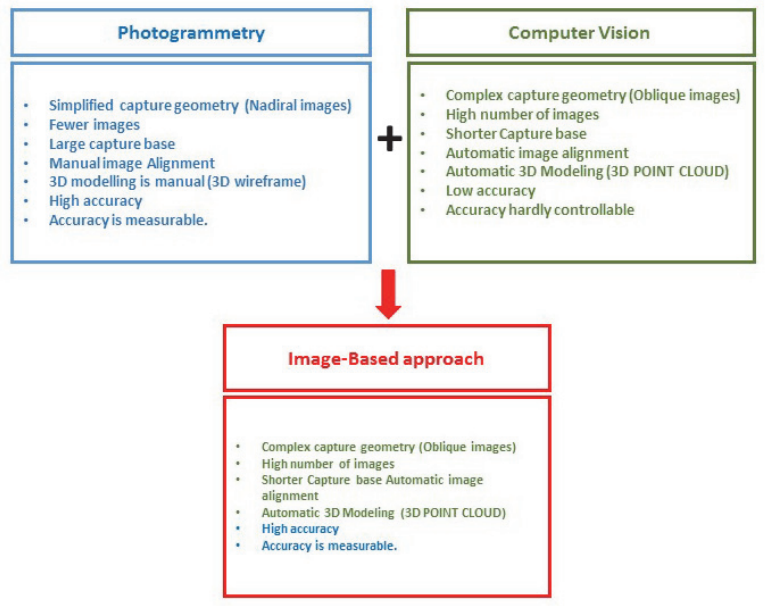

Figure 10: Photogrammetry joints Computer Vision creating Image Based modelling Approach. Advantages and disadvantages are listed. Image based approach inherits the advantages of the two methodology.

\subsection{Range based and image based techniques: some differences.}

The main difference between the two approaches is that with laser scanner, and, in general, with range-based methods it is possible to get in real-time $3 \mathrm{D}$ reconstruction of the object in the form of point cloud. The quality of the model depends on instrument specifications, on the material of the object and minimally by acquisition geometry. With image-based methods, it is now also possible to extract a complete 3D of the object. That's requires a previous photogrammetric elaboration that can be done nowadays fully automatically. The quality of the final $3 \mathrm{D}$ product is given by the original photographic quality of the images and to the capture geometry. (Fassi, 2013)

Range-based methods requires expensive instruments and normally fix, and stable acquisition points. Image based, at the contrary, needs only good photo camera and, as said before, enjoy the freedom typical of the photographic acquisition. For these reasons, especially in the world of architecture, we are facing the return of photogrammetry because cheaper, finally user friendly and very flexible. It can be applied for big architectonic buildings or for little decoration using the same camera and the same software. On the paper, it can be used by everybody, just because the software allows automatic processing, little and no intervention by operators and especially low costs.

However, we have to pay significant attention, because "all that glitters ain't gold" (Prince): many blunders can be made if the measuring phase is underestimated just because it is now automatic and simpler.

The new survey techniques are very promising, but we must not forget the final goal, which is being able to extrapolate fast and immediate information which are useful for the intervention project and for its representation on paper or in a 3D environment. Often automatism means trusting too much about the products that are obtained with little or no effort and this may result in taking big blunders. We must never forget that the survey products must have a metric value and represent in scale and with a predefined accuracy the object as support for the further studies and interpretations.

The main differences between now and yesterday are automatism in image analysis. For this reason it is possible i) to handle huge number of image surveying complex and large object and ii) to model completely, in high resolution and in 3D an object simple or complex. In this way, using only one methods it is possible to extract mono, bi o three-dimensional information that is extract 2D plotting or single points coordinates and moreover, only using image-based techniques, it is possible to have at disposal the $3 \mathrm{D}$ model useful to generate orthophotos or to extract $3 \mathrm{D}$ information.

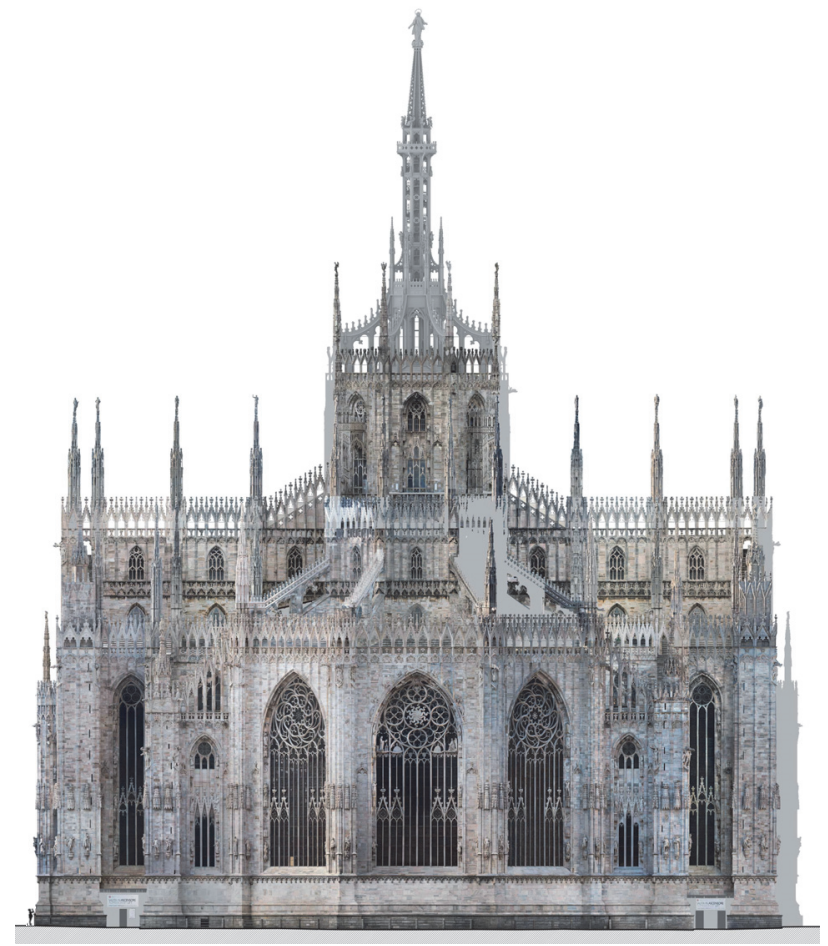

Figure 11: Orthophoto of the East Façade (apse) of the Milan Cathedral (April 2017) at 1:50 representation scale $(4 \mathrm{~mm}$

GSD). 3580 images taken using for different lenses. The orthoimages is the mosaic of 50 single orthophotos created only in a photogrammetric way during 574 hour of processing. The 3D DSM is about 1.5 billion of point. $40 \mathrm{GCP}$ are used to chech and support the elaboration. (Degree thesis of Andrea de Biasi and Hazal Gulsan- 3DsurveyGroup-Polimi)

\section{IN THE FUTURE?}

Today it is not enough simply take and pictures, but it is necessary to develop smart systems able to provide the best graphic medium (possibly in three-dimension) supporting the development and the editing of the project for building architecture. Such systems will mostly be appreciable if they are able to provide automatically quantitative data and allow the relative bill of quantities. The natural evolution of the yard managing is the "smart yard": data information distributed and made available through tablet, portable devices and smart phones with the possibility to update them sharing in real time the changes. 
The survey systems (as photogrammetry and laser scanners) and software able to elaborate raw 3D data as point clouds are developing faster and faster. This acceleration is driven by the new revolution in matter of Building Representation and Build Managing system the so called BIM Systems (Building Information Modelling), well known and widely spread in the world of construction. (Rechichi et al, 2006) They are not yet widely used in the complicate world of $\mathrm{CH}$ (Cultural Heritage) but they are becoming necessary. They are born and developed for the ex-novo planning, but to be considered, to be experiment and to also be applied to the existing housebuilding. The data contained in the model, in the case of degraded existing architectures, in comparison to a new construction, multiply themselves because they define all the information concerning a specific component of the building, rich of variables, specific case by case. Is an evolution, not certainly simple, to wish because a system like this could be able to manage the complete life-cycle from the restoration design phase, through the phase of realization, up to that of use and maintenance.

Exquisitely returning to the theme of the terrestrial photogrammetry, it is sure that today the technique is strongly evolved. As seen, it is a technology able to produce highaccuracy, high-resolution metric images and 3D reconstruction. Once the digital revolution and now the automatism revolution solve the big 3 problems: i) User-friendliness of the photogrammetric process, ii) limitations of manual time consuming intervention and iii) low-cost make photogrammetry the techniques of the future also in the field of restoration. The technology exist, improvement should be done in software or systems that let a very simple use of $3 \mathrm{D}$ and metric data, information sharing and collaborative working. (Fassi, 2015)

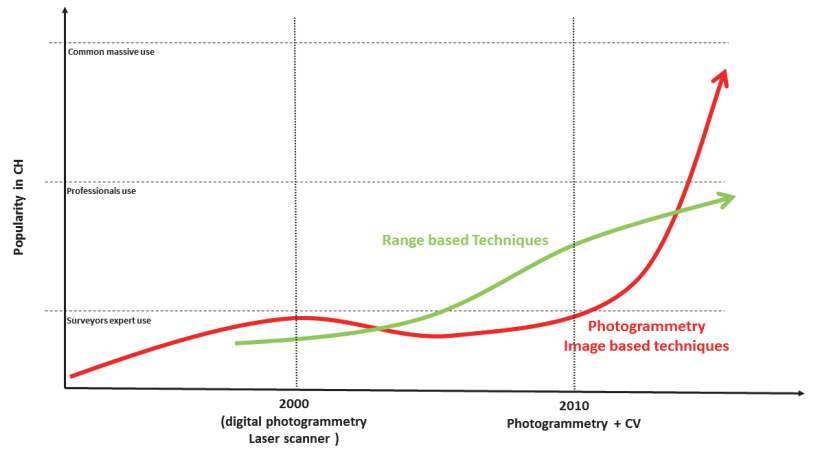

Figure 12: Image base techniques vs Range based techniques, the trend in popularity and use in the field of $\mathrm{CH}$.

Therefore, it become an open field to a not necessarily experienced consumer, if not in the management of the software that brings to the restitution in third dimension of the surveyed object. The first problems that today we meet are not in fact tied up to the photographic takings, but they often refer to the massive structure of information to manage and to the ability and the computational performance to elaborate them.

In the field of the maintenance of historical architectures the natural evolution that we are waiting for is getting a complete reality 3D model of the building. It should functional and useful not only to evaluate and map its state of decay (through the mapping of materials and pathologies) and to define its future conservative intervention, but also to develop the full structural consolidation project and the consequent project of the "new building" to implement and complement of the existing one. It is an interesting passage able to fully provide the real datum "building" as central subject of making architecture for the built-heritage. As a subject always rich of signs, of original details, morphologically unique and absolutely not replicable. Working in this third dimension of the reality could free us from the post-design habits of the unreal rendering, that are poor, statics and few functional representation in supported the project. In short, a modelling that can come in help to gather the unique character that identify every building, to underline the points of strength and weakness, defining virtuous relationships, in the development of the project of use, in continuity and not in substitution in the integrated planning between the new and the existing.

We wish, in conclusion, that the research could keep on developing the photogrammetric method and its use and applicability, in special way inside the laboratories of maintenance in our Schools of Architecture. The future should see the improving of new forms of representation and harvest of data passing from the bi-dimensional to the three-dimensional one. This will help, slim and fasten the procedures and the extrapolation of useful data to the development of the project. It will serve more and more also as stimulus to develop fast and user-friendly hardware and software to use in order to widen the use of shared and smart application in the restoration activities or directly on the yard.

\section{REFERENCES}

Bignardi I., 1986. Ci perdoni Mr Ruskin, La Repubblica, 14 febbraio.

Burgio V., 2009. Dal dagherrotipo di John Ruskin all'improntadi Jorge Otero-Pailos: The Ethics of Dust: Doge's Palace, Venice.

Campanella C., 2017. Il rilievo degli edifici: metodologie e tecniche per il progetto di intervento, Flaccovio Editore, Palermo.

Costantini P., 1986. Ruskin e il dagherrotipo, in Costantini Paolo e Zannier Italo (a cura di), I dagherrotipi della collezione Ruskin, Arsenale, Venezia.

Fassi, F., Achille, C., Mandelli, A., Rechichi, F., and Parri, S., 2015. A new idea of bim system for visualization, web sharing and using huge complex $3 \mathrm{~d}$ models for facility management., Int. Arch. Photogramm. Remote Sens. Spatial Inf. Sci., XL5/W4, 359-366, doi:10.5194/isprsarchives-XL-5-W4-359-2015.

Fassi, F., Fregonese, L., Ackermann, S., and De Troia, V., 2013. Comparison between laser scanning and automated $3 \mathrm{~d}$ modelling techniques to reconstruct complex and extensive cultural heritage areas, Int. Arch. Photogramm. Remote Sens. Spatial Inf. Sci., XL-5/W1, 73-80, doi:10.5194/isprsarchivesXL-5-W1-73-2013.

Kraus, K., 2008. Photogrammetry - Geometry from Images and Laser Scans. Walter de Gruyter, Berlin (Germany).

Melloni M., 1839. Relazione intorno al dagherrotipo, Porcelli, Napoli.

Rechichi, F., Mandelli, A., Achille, C., and Fassi, F., 2016. Sharing High-Resolution models and information on Web: the Web Module of BIM3DSG System, Int. Arch. Photogramm. Remote Sens. Spatial Inf. Sci., XLI-B5, 703-710, doi:10.5194/isprs-archives-XLI-B5-703-2016.

Ruskin J., 2002. Viaggio in Italia, Mondadori, Milano, pag 163 